\title{
Assessment of amplitude of accommodation (AA) in Owerri Municipal Council, Southeast, Nigeria
}

\author{
Akujobi $\mathrm{AU}^{1 *}$, Vincent $\mathrm{CL}^{2}$, Ekenze $\mathrm{CJ}^{1}$, Obioma-Elemba $\mathrm{JE}^{1}$ and Vincent $\mathrm{CC}^{3}$ \\ ${ }^{1}$ Department of Optometry, Imo State University, Owerri, Nigeria \\ ${ }^{2}$ Cypress Eye Centre, Abuja, Nigeria \\ ${ }^{3}$ Department of Nursing Science, Imo State University, Owerri, Nigeria
}

*Corresponding author: Akujobi AU, Department of Optometry, Imo State University, Owerri, Nigeria.

Received Date: November 28, 2018

Published Date: December 10, 2018

\begin{abstract}
Amplitude of accommodation (AA) was measured in 399 consecutive participants, aged 5 to $\geq 55$ years, in Owerri Municipal Council, Southeast, Nigeria using Donders' Push-up-to-blur (PUB) technique; and compared with the average AA derived from Hofstetter's equation. Each participant wore the subjective prescription and the reduced Snellen chart was gradually moved towards the participant until the first sustained blur on the 6/6 (20/20) line was reported. The distance between the test chart and the spectacle plane was recorded as the near point of accommodation (NPA) in centimeters. Dividing 100 by the NPA gave the AA value. The results showed that age and AA were inversely but significantly $(\mathrm{p}<0.05)$ correlated, with the 5-14 and $\geq 55$ years age categories having the highest (17.49D) and least (1.60D) AA values respectively. Males had insignificantly ( $>0.05$ ) higher mean AA (46.74D) than the age-matched females (45.52D), while students were found to have significantly $(p<0.05)$ higher mean AA (11.23D) than other occupation groups. Among all age groups, the total measured mean AA was observed to be significantly $(p<0.05)$ lower than the calculated average AA derived from Hofstetter's equation. Therefore, Hofstetter's equation did not accurately predict the real amplitude of accommodation among various age groups in Owerri Municipal Council, Nigeria.
\end{abstract}

Keywords: Amplitude of accommodation; Push-up method; Hofstetter's equation; Nigeria

\section{Introduction}

When fixation changes from far to near, the crystalline lens varies its focal length (refractive power) in response to changes in the vergence of the incident light. This process is known as accommodation. Amplitude of accommodation (AA) is the maximum refractive power the eyes can exert. It refers to a certain range of object distances for which the retinal image is as sharply focused as possible [1]. It remains a very important parameter in the diagnosis and treatment of accommodative anomalies, as well as the determination of reading addition of presbyopes. Accommodative anomalies are among the most common visual disorders, and they may be associated with symptoms, such as headache, asthenopia, pain in the eye, occasional diplopia, intermittent blurred vision, and swimming of print while reading [2]. Although a study [3] put the prevalence of accommodative anomalies of patients who come to optometry clinics at $20 \%$, AA is rarely incorporated into routine clinical examinations by eye-care practitioners, which in many cases, may result in errors in the assessment of accommodative function and prescription of reading addition.

Amplitude of accommodation diminishes progressively from childhood to old age [4] and is affected by a propensity for near work and also influenced by the general health of the patient, previous use of the ciliary muscle, vascular and glandular defects [5]. The age-related decline in accommodative amplitude occurs almost universally, to less than 2 diopters (D) by age 45-50 years, and within this age group, most persons begin to experience a decline in the ability to focus on close objects, hence, require glasses or bifocal lenses for reading [6].

Furthermore, a study [7] had reported a mean AA of 14.5D among the 6-10 years age group which subsequently diminished more or less regularly, so that at 61-65 years, it came down to $0.8 \mathrm{D}$, with the age of onset of presbyopia in some, being between the ages 
of 31-40 years. However, the average amplitude of accommodation of persons of various ages was calculated using Hofstetter's equation and has been invaluable in predicting the reading addition of presbyopes. According to another study [8], Hofstetter's equation predicted the average amplitude of accommodation as $18.5-(0.30 \mathrm{x}$ patient's age in years), the minimum amplitude of accommodation as 15 - (0.25 x patient's age in years) and the maximum amplitude of accommodation as $25-$ ( $0.40 \mathrm{x}$ patient's age in years). However, the accuracy of this formula in predicting the average amplitude of accommodation has been queried for certain age groups and populations [9].

In addition, a study [10] compared the amplitude of accommodation in different vertical viewing angles among 31 Malaysians aged 18-26 years using the minus-lens method. The amplitude of accommodation was found significantly changed in four sets of viewing angles $(\mathrm{p}<0.001)$, with the mean difference of 2.52D from 20 Degree up-gaze to 40 Degree down-gaze. However, the association of amplitude of accommodation in different viewing angles among genders and age groups was not significant ( $p>0.05$ ) Furthermore, the amplitude of accommodation evaluated by dynamic retinoscopy, push-down and minus lens techniques was measured and compared among 1,298 subjects between 5 and 60 years of age [11]. For the dynamic retinoscopy findings, no significant change was observed between 5 and 19 years of age (mean $\mathrm{AA}=8.3 \mathrm{D}$ ) and between 45 and 60 years of age (mean $\mathrm{AA}=0.6 \mathrm{D})$. Similarly, the amplitude of accommodation among genders and race for different reading postures was shown to be insignificant $(p>0.05)$ [12].

In many instances, accommodative anomalies and nonstrabismic binocular dysfunctions are associated with depletion of accommodative amplitude, especially among occupation groups and populations predisposed to rigorous reading and other near tasks [13]. In urban populations, near tasks are predominant, life expectancy is high, hence, many more people attain older ages and consequently experience depletions in accommodative amplitude. As a result, there is need to generate territory-specific data, which could provide normative AA values for urban populations and also enhance precision in the prescription of reading addition for presbyopes in such populations.

Furthermore, previous investigations into amplitude of accommodation (AA) merely compared the measured AA with the calculated AA derived from Hofstetter's equation $[9,10,14]$, without reporting its distribution among various age-matched demographic groups. The study, therefore, investigated the amplitude of accommodation among diverse population groups and also compared the measured mean AA with the calculated average AA of Hofstetter's formula to ascertain the accuracy of Hofstetter's equation in predicting real amplitude of accommodation in the study-area.

\section{Materials and Methods}

\section{Study-area}

Owerri is the capital of Imo State, Nigeria and has geographical coordinates of $5029 " 0 " \mathrm{~N}$ and 702 2" 0 " E. It occupies an area of approximately $58 \mathrm{Km} 2$ and has an estimated population of 127 , 213 people (males $=62,990$; females $=64,223$ ) based on the 2006 National Census Exercise, with about 17, 000 households, including shops and offices. It has the highest number of schools, hospitals, educational institutions, business outfits, government ministries and parastatals in Imo state.

It is bounded on the North by Amakohia, on the Northeast by Uratta, on the East by Egbu, on the Southeast by Naze, on the South by Nekede and on the Northwest by Irete. The municipal council is made up of five main villages; Umuoyima, Umuororonjo, Umuonyeche, Amawom and Umuodu. It also has the layout of Ikenegbu, Aladinma, Trans-Egbu, New Owerri, Works Layout and Uratta road housing estates. Owerri Municipal Council has 2 geological regions; the coastal plain and a plateau portion.

The vegetation is typically rainforest, although some parts consist of Guinea savanna due to poor environmental management and pollution. It has a mean annual rainfall of about 2,250$2,500 \mathrm{~mm}$ with a mean temperature of $25-270 \mathrm{c}$ and a relative humidity of $80 \%$. It has 72 health institutions, 28 primary schools, 8 secondary schools, 2 universities and one college of education with the inhabitants being mostly civil servants, students, traders and artisans.

\section{Study-population and sample size}

The study-population comprised of the 127, 213 persons estimated by the 2006 National Census Exercise. A sample size of 399 consecutive participants was drawn using the Taro Yamane's formula for determination of minimum sample size.

\section{Ethical considerations}

Ethical protocols established by the Helsinki Declaration on Human Experiments were adopted. Ethical approval for the study was obtained from the Imo State Ministry of Health, while oral informed consent of the participants was obtained prior to examinations.

\section{Procedure for data collection}

The Donders' push-up-to-blur (PUB) method was adopted for the measurement of amplitude of accommodation. Each participant was clerked and subjected to a comprehensive eye examination which included; distant and near visual acuity, ophthalmoscopy and static retinoscopy. Subjective refraction and refinement techniques were used to determine the prescription. Participants were excluded if they had amblyopia, accommodative anomaly, recent cycloplegic refraction, ocular surgery, cataract and ocular pathologies that could alter the accommodative status.

Each participant wore the subjective prescription. The reduced Snellen chart was gradually brought closer to the participant until the first sustained blur on the 6/6 (20/20) line was reported. The distance from the chart to the spectacle plane was measured as the near point of accommodation (NPA) in centimeters. One hundred (100) was divided by the NPA to obtain the AA.

\section{Statistical analysis}

Data were analyzed using Chi-square (X2) statistical method. 


\section{Result}

Out of the 399 consecutive participants examined for amplitude of accommodation (AA), males (151) constituted 37.84\% and females (248) $62.16 \%$ of the study population. The $15-24$ years age-group had the highest number of participants among both males (61) and females (150) while the $\geq 55$ years category had the least male (3) and female (2) participants as shown in (Table 1).

Table 1: Age and gender distribution of sample population in Owerri Municipal Council.

\begin{tabular}{|c|c|c|c|}
\hline Age (Years) & Males (\%) & Females (\%) & Total (\%) \\
\hline $5-14$ & $22(14.6)$ & $30(12.1)$ & $52(13.0)$ \\
\hline $15-24$ & $61(40.4)$ & $150(60.5)$ & $211(52.9)$ \\
\hline $25-34$ & $34(22.5)$ & $39(15.7)$ & $73(18.3)$ \\
\hline $35-44$ & $27(17.9)$ & $20(8.1)$ & $47(11.8)$ \\
\hline $45-54$ & $4(2.6)$ & $7(2.8)$ & $11(2.8)$ \\
\hline$\geq 55$ & $3(2.0)$ & $2(0.8)$ & $5(1.3)$ \\
\hline Total & $151(100)$ & $248(100)$ & $399(100)$ \\
\hline
\end{tabular}

The 5-14 years age category recorded the highest mean AA (17.49D) followed by the 15-24 years group with a mean AA of $10.70 \mathrm{D}$, while the $\geq 55$ years group had the least AA of $1.60 \mathrm{D}$. Across gender, males (46.74D) had insignificantly ( $p>0.05)$ higher amplitudes than their age-matched female counterparts (45.52D).

Four occupation groups; students, civil servants, traders and farmers were identified and evaluated. Among these, more students (326) were sampled than other groups, while the least number of participants was found among farmers (2) (Table 2). Students had the highest mean AA of 11.23D among the occupation groups, followed by traders (5.6D), while farmers recorded the least mean AA of 1.75D.

Table 2: Occupation distribution of sample population in Owerri Municipal Council.

\begin{tabular}{|c|c|c|}
\hline Occupation & Frequency & Frequency(\%) \\
\hline Students & 326 & 81.7 \\
\hline Trading & 24 & 6 \\
\hline Civil service & 47 & 11.8 \\
\hline Farming & 2 & 0.5 \\
\hline Total & 399 & 100 \\
\hline
\end{tabular}

The 5-14 years group had a mean AA of 17.49D with a calculated average AA of 15.65D using Hofstetter's formula, while the $\geq 55$ years age group recorded the least mean AA of $1.60 \mathrm{D}$ with a corresponding average AA of 2.00D calculated with Hofstetter's equation (Table 3 ).
Table 3: Demographic distribution of amplitude of accommodation (AA) in Owerri Municipal Council.

\begin{tabular}{|c|c|c|c|}
\hline Demographic variables & Mean AA (Diopters) & $\mathrm{X}^{2}$ cal. & p-value \\
\hline \multicolumn{4}{|c|}{ Age (Years) } \\
\hline $5-14$ & 17.49 & 21.65 & 0.00061 \\
\hline $15-24$ & 10.7 & & \\
\hline $25-34$ & 7.7 & & \\
\hline $35-44$ & 5.4 & & \\
\hline $45-54$ & 3.3 & & \\
\hline$\geq 55$ & 1.6 & & \\
\hline \multicolumn{4}{|c|}{ Gender } \\
\hline Males & 46.74 & 0.016 & 0.899 \\
\hline Females & 45.52 & & \\
\hline \multicolumn{4}{|c|}{ Occupation } \\
\hline Students & 11.23 & 8.08 & 0.044 \\
\hline Traders & 5.61 & & \\
\hline Civil servants & 4.71 & & \\
\hline Farmers & 1.75 & & \\
\hline
\end{tabular}

\section{Discussion}

The 5-14 years age group recorded the highest mean amplitude of accommodation (AA) (17.49D), followed by the 15-24 years category, with a mean AA of $10.70 \mathrm{D}$. The least mean AA was observed among the $\geq 55$ years group, where a mean AA of $1.60 \mathrm{D}$ was recorded. The mean AA values were found to be significantly $(p<0.05)$ and inversely correlated with age. The result corroborates those of previous studies $[4,6,7,15,16,17]$ and therefore strengthens corroborative evidences for the declination of AA with age but disagrees with the findings of Majumder \& Ying [11]. The discrepancy between the findings of the present study and those of a previous study [11] may be predicated on variance in the study design of both studies. While the present study investigated the amplitude of accommodation at the primary position of gaze, the previous study [11] examined the AA from four sets of viewing angles. AA values obtained from these angles, undoubtedly, should differ from those at the primary position of gaze as a result of the altered tonicity of the relevant extra ocular muscles involved in ocular motility.

The gender distribution of AA showed that males had a higher mean AA of 46.74D than their age-matched female counterparts (45.52D), although the difference was not statistically significant ( $p>0.05$ ). The result compares very closely with the findings of a recent study [13] which reported that mean AA distributions were not significantly correlated with gender. Although the higher mean AA observed among the male participants does not conform to any known explanation, it is not unlikely that males may have stronger iris sphincter muscles which are responsible for pupil constriction in accommodation. On the other hand, the result disagrees with the submissions of another study [18] where females exhibited significantly higher AA than the males. The younger age distribution of the females could have been accountable for the discrepancy in 
the findings of the previous study and the present one where both genders were age-matched.

Among the occupation groups, students were found to have the highest mean AA (11.23D), followed by traders (5.61D), civil servants (4.71D) and farmers who had the least mean AA of 1.75D. Moreover, the observed differences in mean amplitude of accommodation within the occupation groups were statistically significant $(\mathrm{p}<0.05)$. The findings do not agree with those of a previous study [19] where depletion of AA was established among occupation groups predisposed to rigorous reading and other near works. On the contrary, students examined in the present study did not record a lower mean AA despite rigorous academic indulgences; however, the higher AA observed among students is most likely attributed to the age of the students, who were younger and therefore, exhibited higher amplitudes. Furthermore, it is likely that if the students' amplitudes were compared with an age-matched non-student population, the findings may have been in good agreement with those of the previous study [19]. The observed distribution of mean AA among occupation groups conforms to logical explanations; the mean AA value of traders (5.61D) may suggest that most traders within the study-area were relatively young; moreover, trading is not a near-specific task and therefore, does not impose a significant demand on the accommodative mechanism. The mean amplitude of accommodation of civil servants (4.71D) was found to be lower than that of traders because civil servants are predisposed to lengthy hours of near tasks, which could result in the depletion of AA. The least mean AA value of $1.75 \mathrm{D}$ recorded by farmers may imply that most of the farmer were within the $\geq 55$ years age group and had amplitudes which were already depleted as a result of age and other geriatric-related conditions (Table 4).

Table 4: Age distribution of measured mean AA and Hofstetter's average AA in Owerri Municipal Council.

\begin{tabular}{|c|c|c|}
\hline Age (Years) & $\begin{array}{c}\text { Measured Mean AA } \\
\text { (D) }\end{array}$ & $\begin{array}{c}\text { Average AA (D) by } \\
\text { Hofstetter (18.5- } \\
\text { (0.3XAge) }\end{array}$ \\
\hline $5-14$ & 17.49 & 15.65 \\
\hline $15-24$ & 10.7 & 12.65 \\
\hline $25-34$ & 10.7 & 9.65 \\
\hline $35-44$ & 5.4 & 6.65 \\
\hline $45-54$ & 3.3 & 3.65 \\
\hline$\geq 55$ & 1.6 & 2 \\
\hline Total & 46.19 & 50.25 \\
\hline
\end{tabular}

The difference between the total measured mean AA (46.19D) and the average AA calculated with Hofstetter's equation (50.25D) was statistically significant $(\mathrm{p}<0.05)$. More so, all age groups recorded lower mean AAs than average AAs derived from Hofstetter's equation. The mean AA of the 5-14 years age group did not conform to this pattern and may most likely be a statistical outlier.

The result of the present study agrees strongly with that of another study [10] where it was found that the amplitude of accommodation of Ghanaian children did not agree with the agepredicted values of Hofstetter's equation. Although the study [10] reported highervalues than those derived from Hofstetter's equation while the present study reported lower values, both queried the accuracy of Hofstetter's equation for calculating the amplitude of accommodation in all age groups and populations. Furthermore, the findings of the present study corroborate the evidence of other studies $[14,15,20]$ against the accuracy of Hofstetter's equation. Although the studies sampled 6-12, 6-18 and 6-10-year-old school children respectively, the measured mean AA was found to be lower than that calculated with Hofstetter's equation in the 6-12- and 6-10-years age categories. Both studies $[14,20]$ therefore suggested that Hofstetter's equation did not accurately predict the amplitude of accommodation of children within these age groups.

\section{Conclusion}

The depletion of AA with advancing age, opined by previous studies, was re-established in the present study. Normative data for mean AA were generated for various age and population groups in Owerri Municipal Council, Nigeria and will therefore provide an empirical baseline for future comparative studies. Males recorded higher AA than females, while students had higher AA than other occupation groups. Furthermore, the present study corroborated previous evidences against the accuracy of Hofstetter's equation in predicting real amplitude of accommodation among various age groups, hence, clinical assessment of AA is recommended over Hofstetter's equation.

\section{Acknowledgement}

The authors are grateful to the Department of Optometry, Imo State University, Owerri, Nigeria for granting the permission to use the Optometry Clinic throughout the period of the study.

\section{Conflict of Interest}

The authors declare that there were no personal or financial interests which may have inappropriately affected the conduct or the results of the study.

\section{References}

1. Atchinson DA (1994) Clinical measurement of amplitude of accommodation. Australian Optometry Magazine 15.

2. Bailey R (1998) Assessing the predictive ability of the test-positive findings of an elementary school vision screening. Optom Vis Sci 75(9): 682-691.

3. Karania R, Evans BJ (2006) The Mallet Fixation Disparity Test: Influence of test instructions and relationship with symptoms. Ophthalmic Physiol Opt 26(5): 507-522.

4. Majumder Cand, Ying LS (2015) Comparison of amplitude of accommodation in different vertical viewing angles. Optometry and Visual Performance 3(5): 276-280.

5. Leon A, Estrada JM, Rosenfield M (2016) Age and the amplitude of accommodation measured during dynamic retinoscopy. Ophthalmic Physiol Opt 36(1): 5-12.

6. Duane A (1912) Normal values of accommodation at all ages. JAMA LIX (12): 1010-1013.

7. Chattopadhyay DN, Seal GN (1984) Amplitude of accommodation in different age groups and age of onset of presbyopia in Bangalee population. Indian J Ophthalmol 32(2): 85-87.

8. Porcar E, Montalt JC, Pons AM, Espana-Gregori E (2018) Symptomatic accommodation and binocular dysfunctions from the use of flat-panel displays. Int J Ophthalmol 11(13): 501-505. 
9. Ikaunieks G, Panke K, Seglina M, Svede A, Krumina G (2017) Accommodative amplitude in school-age children. Proceedings of the Latvian Academy of Sciences 71(5): 387-391.

10. Ovenseri-Ogbomo GO, Kudjawu EP, Kio FE, Abu EK (2012) Investigation of amplitude of accommodation among Ghanaian school children. Clinical and Experimental Optometry 95(2): 187-191.

11. Majumder C, Ying LS (2015) Comparison of amplitude of accommodation in different vertical viewing angles. Optom Vis Perf 3(5): 276-280.

12. Leon A, Estrada JM, Rosenfield M (2016) Age and the amplitude of accommodation measured using dynamic retinoscopy. Ophthalmic Physiol Opt 36(1): 5-12.

13. Majumder C, Roslan ENBT, Ghosh P (2018) Comparison of amplitude of accommodation in different reading postures. JOJ Ophthalmol 6(3): 1-5.

14. Hashemi H, Nabovati P, Khabazkhoob M, Yekta A, Emamian MH, et al. (2018) Does Hofstetter's equation predict the real amplitude of accommodation in children? Clin and Exp Optom 101(1): 125-128.
15. Ovenseri-Ogbomo GO, Oduntan OA (2017) Comparison of measured with calculated amplitude of accommodation in Nigerian children aged six to 16 years. Clinical and Experimental Optometry 101(4): 571-577.

16. Sterner B, Gellerstedt M, Sjostrom A (2004) The amplitude of accommodation in 6-10-year-old children not as good as expected. Ophthal physiol Opt 24: 246-251.

17. Ovenseri-Ogbomo GO, Nosakhoro E (2018) Age, amplitude of accommodation and near addition power of adult Nigerians. Journal of the Nigerian Optometric Association 20(1): 14-19.

18. Hofstetter HW (1965) A longitudinal study of amplitude changes in presbyopia. American Journal of ophthalmology Arch American Academy of optometrists 42: 3-8.

19. Donders FC (1864) On the anomalies of accommodation and refraction of the eye. London. New Sydenham Society.

20. Duane A (1912) Normal values of the accommodation of all ages. Journal of the American Medical Association 59: 1010-1013. 